\title{
Research and Implementation of the Cloud Platform Based on the B-learning
}

\author{
$\mathrm{Xu}$ Chao ${ }^{1} \& \mathrm{Ge}$ Hongmei $^{1}$ \\ ${ }^{1}$ Department of the Information Management, XuZhou College of Industrial Technology, XuZhou, China \\ Correspondence: Xu Chao, Department of the Information Management, XuZhou College of Industrial \\ Technology, XuZhou, China. E-mail: xuch@mail.xzcit.cn
}

Received: May 2, 2012 Accepted: May 21, 2012 Online Published: June 8, 2012

doi:10.5539/cis.v5n4p77 URL: http://dx.doi.org/10.5539/cis.v5n4p77

\begin{abstract}
The paper puts a "cloud" learning platform mode. In order to improve the quality of education and teaching and solve the problems such as single teaching systems, the gap between classroom teaching and online teaching and less interaction between the teacher and students and so on. First, force on the application of cloud computing, cloud learning and cloud platforms, we analysis and compare to characteristics of the traditional learning platform, and propose a method that based on the B-learning thinking for the cloud learning platform. Then we give an instance of practice application and it proves that the establishment of cloud study platform has improved the efficiency of the teachers' classroom, the students' independent learning, teacher-student interaction, and so on. It is of great significance for promoting the teaching techniques of innovation
\end{abstract}

Keywords: B-learning, cloud platform, education technology.

\section{Introduction}

With the development of the computer applications, multimedia technology and Internet technology, how to combine the Internet with teaching and education has become a research focus. There are a lot of learning systems now, such as e-learning system, intellectual exchange Technology online learning system, beads ZhuHaiaozhuoer Software Ltd. Aozhuo Er learning the world and so on. However, they have some common questions: (1) single system. These system fail to share learning resources, and each system not only need high hardware costs, but also need someone to maintain and update the system; (2) classroom instruction and online teaching does not combine teacher-student interaction enough; (3) curriculum goals and objectives of software design does not match the self-learning system, and it need to be sound (Bruce, Marsha, \& Emily, 1999; Robert, Gu, Michael, \& Zhang, 2009).

In the information age which marked by multimedia and network technology, a more realistic education thought is Blending-learning (referred to as the B-learning, the blended learning), that is, "the combination of Dominated - subject" education thought. Practice has proved that the best learning results come only from the combination of the leading role of the teacher with student self-learning. B-learning or blended learning combines the advantages of traditional learning and E-Learning (Josh, 2004; He, 2010). Based on the B-learning ideas and cloud technology, we establish a cloud learning platform. Figure 1 depicts the interaction between the modules of the hybrid learning system.

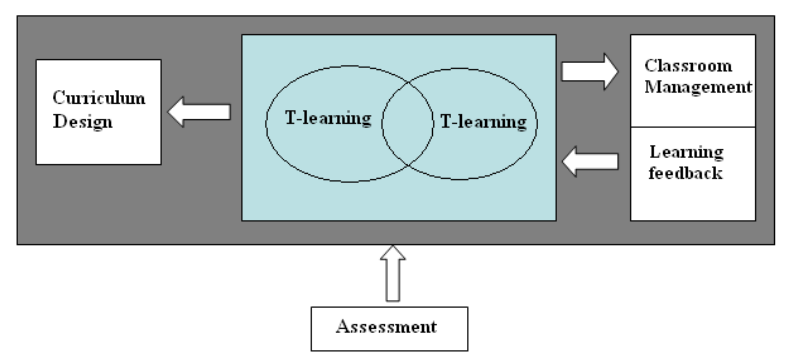

Figure 1. Modules of the hybrid learning system 


\section{The Designe of Cloud Learning Platform}

\subsection{Cloud Computing}

Cloud computing is location independent computing, whereby shared servers provide resources, software, and data to computers and other devices on demand, as with the electricity grid. Cloud computing is a natural evolution of the widespread adoption of virtualization, service-oriented architecture and utility computing. Details are abstracted from consumers, who no longer have need for expertise in, or control over, the technology infrastructure "in the cloud" that supports them (Danielson \& Krissi, 2008).

Cloud computing will be distributed in a large number of distributed computing on the computer, rather than the local computer or remote server. Cloud computing aggregation and distribution of information processing firstly, and then provide services to customers through the network. Thus, the services provided cloud computing than traditional Internet service has undergone major changes. So many courses and communications that are difficult to achieve under the traditional conditions can be achieved under the strong power of the "cloud". In addition to technical support from the cloud outside of the education and learning, new ways of learning that according to the ideas and concepts of cloud are also cloud study. Figure 2 illustrates the service of cloud computing.

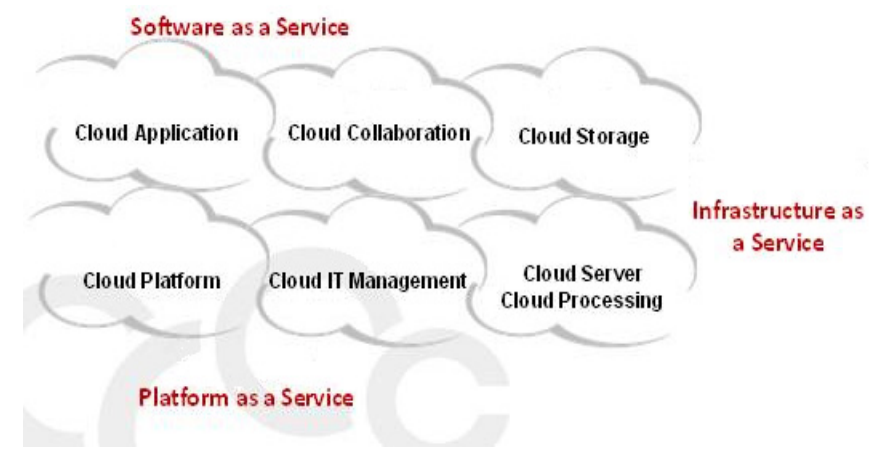

Figure 2. The service of cloud computing

\subsection{Cloud Learning}

Cloud learning is a network learning technologies that based on the cloud computing. It can realize the resources sharing and interaction between teachers and students. It uses distributed processing and parallel co-processing technologies to produce a new interactive learning service that can combine the learning cloud all over the network. It is extension and development on the cloud computing, but a new application field over the cloud computing. It is the same as the thought of e-learning.

Cloud learning is a new teaching model to student. Students become the subject and the new learning model release a lot of time and space for students. It creates a mobile and self-learning environment. In mobile learning, students use mobile devices to access the network anytime, anywhere to get the required information. They do not limited to the computer, and the learning space has greatly expanded and extended. Cloud rich learning integrates teaching resources and creates a new learning space that is information security, information collaboration and information sharing. It provides effective technical support for the independent learning and brings the convenience tools of learning to improve student learning (Yang, Huang, \& Zhong, 2010).

On the basis of cloud learning, we increase the teachers guide, inspire, monitoring and so on to the platform that fully reflects the leading role of teachers and the dominant position of students.

\subsection{Cloud Platform}

\subsubsection{The Basic Architecture of Cloud Platform}

The architecture of cloud platform is the underlying technology to support the cluster background equipment, access and traffic scheduling; cross-platform technology for a variety of different courses in different disciplines of heterogeneous database metadata harvesting and management; on this basis, colleges and universities to existing servers into a unified cloud platform, a unified service interface for users to learn applications.

In the cloud learning platform, the knowledge is in the form of study cloud that hosted in the cloud network. Study cloud is cloud resources integrate a certain organizational form of knowledge into one node, and then connected 
between the node to the formation of rich and powerful resource network. Learning system consists of the entire study cloud network and many clouds terminal learning machine.

Cloud terminal learning machines are lightweight client, such as mobile phones, PDA, browser, etc., and they have the property of low cost, portable, interactive and friendly and so on. Users can visit the learning cloud in anytime and anywhere if they want. Learners needn't care about their position, and they can just query the keywords to obtain educational resources from around the world, and then choose the learning content needs to learn. The cloud terminal learning machine and study cloud can achieve self-interactive learning. Figure 3 is the architecture of cloud platform.

\subsubsection{The Structure of Cloud Learning Platform}

The cloud learning platform consists of the main platform and the sub-node platform. The two types of platform have the same function that they can provide application services for the local learning roles and division of the difference. The differences of the two types are that the main platform servers for the users and inner data's scheduling, and the sub-node platform servers for the main platform. However, from the perspective of cloud platform, the main platform and sub-node platform is a whole and constitute independent services of a learning platform.

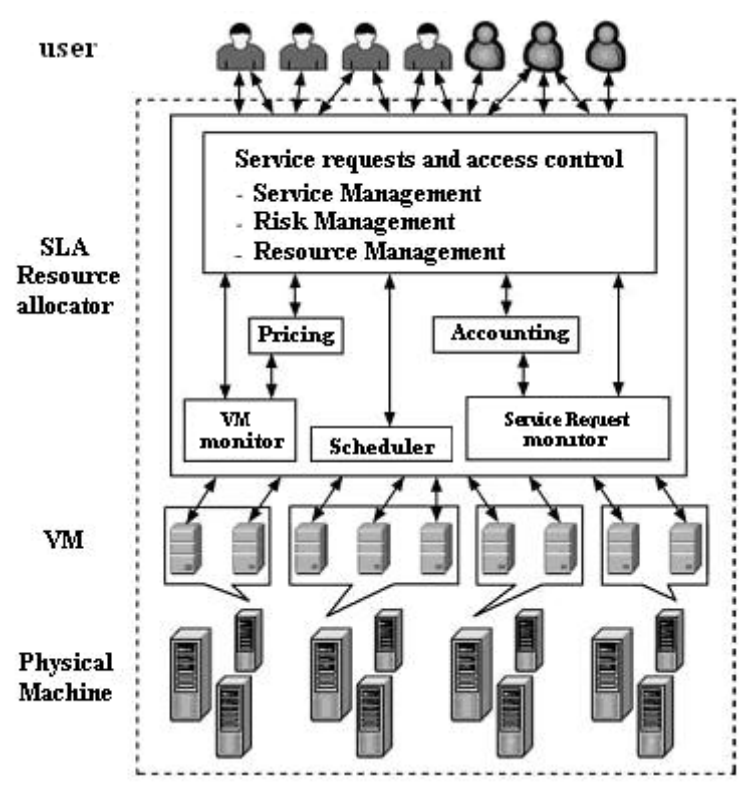

Figure 3. Architecture of cloud platform

\subsubsection{Interface of Cloud Learning Platform}

Cloud learning platform uses the interface of Web forms to provide students with learning resources service. The user interface for students include course literature search and browse, course information and dynamic, course reference, papers and job submission services, and video conferencing blog RSS online communication. The user interface for teachers include material information, academic reference management, course management and other professional applications, pre-class preparation released, dynamic information dissemination, job correcting, video instruction, interactive communication and other necessary services (Liu, 2004; Wang, 2010).

\subsubsection{Data Management of Cloud Learning Platform}

We use the database of two schools as an example to illustrate the data management. We suppose the database of school A as the Sysbase and the database of school B as the dbase. The cloud platform uses the database virtualization technology and Web middleware to unify manage and schedule the various nodes of heterogeneous database. At the same time, we use the technology of metadata harvesting to re-create a form of data at each point, and then we can rely on the database to ensure that the cloud platform will improve in speed and space. Users can submit a query through any one of the middleware provided by the Web service interface. The query through decomposition, routing to network with other middleware, implementation, and ultimately return the results to the client. The method is as follows: 
define [server1.db1.info $=a][$ server2.db2.infomation $=b]$

select [a. ${ }^{*}[b . *]$ from $[a][b]$

where [a.course $=$ course], [a. documents $=$ documents], [b.course $=$ course] and [b.documents $=$ documents].

We suppose that:

server1.db1.info $=$ a the middleware of database of School $A$;

server2.db2.info $=b$ the middleware of database of School B;

The query is divided as follows:

(1) define [Select $a .{ }^{*}$ from [server1.db1.info $\left.=a\right]$ where [a.course $=$ course] and [a.documents $=$ documents] $=$ a1]

(2) define [Select $b .{ }^{*}$ from [server2.db2.info $\left.=b\right]$ where [b.coursename $=$ courseName] and [b.documents $=$ documents] $=b 1]$

Combine the data from (1) and (2) to get follow sub-query:

Select [a. *] [b. *] from [a1] [b1] where ...

Constituted by the middleware, data sharing network has high flexibility, integration middleware in the cloud only need to install the node platform, IP network link configuration can be easily extended to data-sharing network.

\subsubsection{Cloud Platform Services}

The resources in the cloud environment is the Resource cloud via the Internet to build an open. The ideal goal of cloud users access Internet terminal to be able to obtain the required document resources.

1) In the cloud, and the actual use of pay, Resource services cloud, technically speaking, requires the use of cloud computing technology-based information support system. Hardware resources services cloud environment to achieve efficient, orderly, scalable, high-security applications;

2) In the organization of resources, need to build an open resource services cloud to achieve the integration and sharing of resources and orderly scheduling, and reveal the depth, low power consumption and efficient resource security system, the core of the Union of resource development and services;

3) In the Resource management and services, entry through the standardization of resources, resource organization, resource retrieval, resources, services, applications and billing tool interface services resources, service providers, service tools, service personnel, service innovation, integrated into a unified cloud platform mode, Manufacturing resources, resource integration, resource services, and resource utilization to stakeholders blend;

4) In the business model, need to implement cloud computing on-demand pay to achieve the unification of the basic services and value-added services, free services and fee-based services, copyright protection and sharing of resources utilization.

\section{Case Study of Cloud Learning Platform}

In this section, we use the course of "C\# Programming" of XuZhou College of Industrial Technology as an example to illustrate the cloud learning platform. The course is computer software technology expertise of the professional core courses, first of all teachers in the learning platform in the clouds create their own teaching network, a node as a learning platform for the Web Access. The " $\mathrm{C}$ \# Programming" course syllabus, lecture notes, courseware, problem sets, papers, videos and other content resources, curriculum integration of the Internet to provide services for students. Students can query the overall design of courses, curriculum knowledge goals, what kind of ability to achieve goals from the platform, and you can review each lesson of the knowledge points or on-line answer the question and so on. Figure 4 is the method of B-Learning that base on the cloud learning platform to this course. 


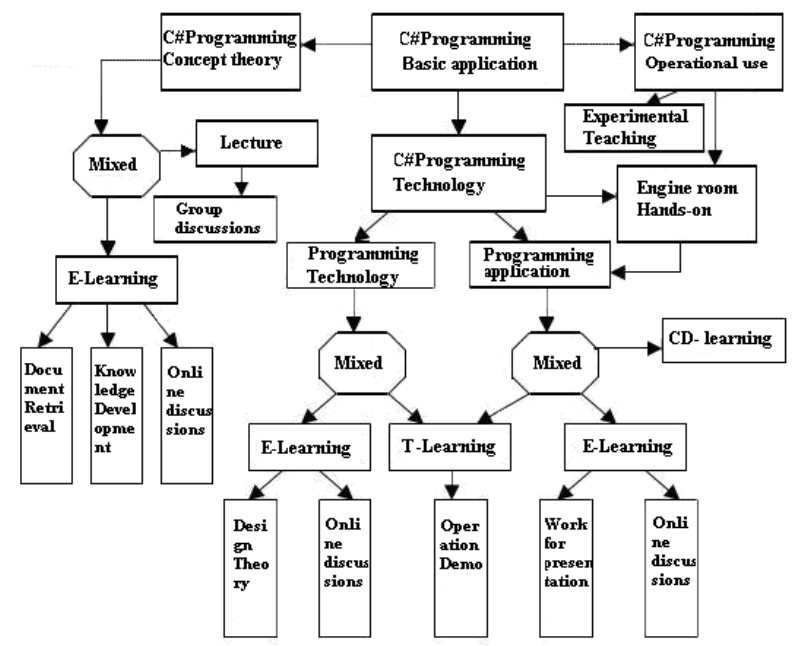

Figure 4. Method of B-Learning that base on the cloud learning platform for the course of "C\# programming"

When we have this platform, teachers can post the preview knowledge online before the class and key knowledge after the class. Student can enter the forum to ask questions, online counseling, talk, discussion, interaction with teachers and so on. We can use this platform to get the achievement of human-computer interaction and teacher-student interaction. And the cloud platform has solved the problem of traditional platform.

\subsection{The Resources of Cloud Learning Platform are Shared and Needn't Special Maintenance Personnel for Each System}

Learning networks are considered as nodes sinking into the cloud learning platform. It is facilitate to search information. Study system is not sole and the resource can be gotten by anyone who is a part of whole network. For example in learning "C \# Programming" courses, you want to check the "uncertainty" Concept, not only can search for Explanation of Terms in computers, you can check the explanation in mathematics, because it is cross-platform, multiple database related. Another example is learning "Animation Design" curriculum. If students interested in the company of the apple, they can retrieve from the platform, direct access to the apple company background, experience, products and so on. It can expand the students' knowledge and improve student's learning initiative.

Meanwhile, the construction of cloud-learning platform is a platform that is economic efficiency, technical means full integration of learning resources, and ultimately maximize the learning resources. Learning Services to provide services based entirely on the Web, most universities no longer need to purchase a traditional hardware server, but do not need someone to maintain and update, just through the terminal access ever-learning platform in the ubiquitous network, you can experience a variety of services, access to resources like "water is just twisted the faucet", as a convenient simple.

\subsection{Classroom Teaching with Online Teaching will be Organically Combined to Realize between Teachers and Students, between Students in Regular Online Interaction}

Cloud learning platform includes information dissemination before class, video teaching, RSS online communication, job submission and other functions, students learning platform through the "pre-class preparation", the preview before the course; through "extra-curricular collaborative learning" curriculum. Besides review, RSS can also communicate online, job submission, effective interaction with the teachers; it is not only to play the leading role for teacher as a teacher guide and inspiration, but also fully reflect the student's status is in line with B-learning education thought.

\subsection{B-learning-Based Self-learning Modules Solve the Mismatch between the Course Goals and Objectives of Software Design}

The current course of study system is both to support teachers' teaching module and the students' self-learning module. However, the function is often more complete in teaching modules, but the function of self-learning modules are relatively weak, even in passing. In cloud learning platform, we design an extra-curricular collaboration system. It bases on the curriculum objectives and make the "game, role, task" approach into the cooperative system. When students come into the system, they can get the task that teacher send and can solve it 
using their knowledge. Meanwhile, the student can get the audit and point too. The establishing of B-learning-based self-learning module can effectively solve the mismatch between the curriculum goals and objectives of software design.

\section{Conclusion}

The improvement of information technology brings new challenge for the education technology. Cloud is one of newest technology in modern information technology, and it provides a full range of guidance to education technology. The construction of Cloud-based B-learning Learning Platform promotes the students' learning and changes the model of teaching. It improves the students' learning motivation. Cloud learning platform is still in the initial stage now, and exist many problems such as security, performance, cost and other troubles. In this paper, we have three contributions: (1) The resources of cloud learning platform are shared and needn't special maintenance personnel for each system. (2) Classroom teaching with online teaching will be organically combined to realize between teachers and students, between students in regular online interaction. (3) B-learning-based self-learning modules solve the mismatch between the course goals and objectives of software design.

\section{References}

Bruce, J., Marsha, W., \& Emily, C. (1999). Models of Teaching. Boston: Allyn and Bacon.

Danielson, K. (2008). Distinguishing Cloud Computing from Utility Computing. Retrieved from http://www.ebizq.net/blogs/saasweek/2008/03/distinguishing_cloud_computing/

He, K. (2010). "Dominated-Subject" the basic theory of teaching structure. Retrieved from http://www.etc.edu.cn/articledigest9/zhu-dao.htm

Josh, B. (2004). What Works in Blended Learning. Retrieved from www.learningcircuits.org/2003/ju12003/bersin.htm

Liu, Y. (2004). The Design Process of Hybrid Learning. Modern Educational Technology, 14(4), 77-78.

Robert, L. G., Gu, Y., Michael, S., \& Zhang, W. (2009). Computand storage clouds using wide area high performance network. Future Generation Computer Systems, 25(2), 179-183. http://dx.doi.org/10.1016/j.future.2008.07.009

Wang, H. (2010). Construction and Implementation of "Cloud Library" Platform. Information Studies: Theory \& Application, 10(33), 108-111.

Yang, Y., Huang, C., \& Zhong, B. (2010). An Exploration of Cloud Learning Based on Cloud Computing. Modern Educational Technology, 9(20), 108-111. 